\title{
Comparison of LDL fatty acid and carotenoid concentrations and oxidative resistance of $L D L$ in volunteers from countries with different rates of cardiovascular disease
}

\author{
Anthony J. A. Wright ${ }^{1}$, Susan Southon ${ }^{1}$, Mridula Chopra :, Anita Meyer-Wenger ${ }^{3}$, Ulrich Moser ${ }^{3}$, \\ Fernando Granado ${ }^{4}$, Begoña Olmedilla ${ }^{4}$, Bernice Corridan ${ }^{5}$, Isabelle Hinninger ${ }^{6}$, Anne-Marie Roussel ${ }^{6}$, \\ Henk van den Berg ${ }^{7}$ and David I. Thurnham ${ }^{2}$ \\ ${ }^{1}$ Institute of Food Research, Colney, Norwich NR4 7UA, Norfolk UK \\ ${ }^{2}$ University of Ulster, Coleraine BT52 1SA, Northern Ireland, UK \\ ${ }^{3}$ F. Hoffmann-La Roche Ltd, CH 4002-Basle, Switzerland \\ ${ }^{4}$ Clinica Puerta de Hierro, 28035-Madrid, Spain \\ ${ }^{5}$ University College Cork, Cork, Republic of Ireland \\ ${ }^{6}$ UFR des Sciences, Pharmaceutiques et Biologiques, 38700-La Tronche, France \\ ${ }^{7}$ TNO Nutrition and Food Research Institute, 3700-Zeist, The Netherlands
}

(Received 12 January 2001 - Revised 23 July 2001 - Accepted 31 August 2001)

\begin{abstract}
Within Europe there are differences in cardiovascular disease (CVD) risk between countries and this might be related to dietary habits. Oxidative modification of LDL is suggested to increase the risk of CVD and both the fatty acid and antioxidant content of LDL can affect its oxidation. In the present study, concentration of LDL fatty acid and antioxidant micronutrients (tocopherols and carotenoids) and ex vivo oxidative resistance of LDL (lag phase) was compared in volunteers from five countries with different fruit and vegetable intakes and reported rates of CVD. Eighty volunteers (forty males, forty females per centre), age range 25-45 years, were recruited from France, Northern Ireland, UK, Republic of Ireland, The Netherlands, and Spain, and their LDL composition and lag phase were measured. There were some differences in LDL carotenoid and $\alpha$-tocopherol concentrations between countries. $\alpha$-Tocopherol was low and $\beta$ - $+\gamma$-tocopherol were high $(P<0 \cdot 001)$ in the Dutch subjects. $\beta$-Carotene concentrations were significantly different between the French and Spanish volunteers, with French showing the highest and Spanish the lowest concentration. LDL lycopene was not different between centres in contrast to lutein, which was highest in French (twofold that in the Dutch and Spanish and threefold that in Northern Ireland and the Republic of Ireland, $P<0 \cdot 001$ ). However absolute LDL saturated, monounsaturated, polyunsaturated and total unsaturated fatty acid concentrations were different between countries $(P<0.001$, total unsaturated highest in Northern Ireland) there was little difference in unsaturated:saturated fatty acid concentration ratios and no difference in polyunsaturated:saturated fatty acid concentration ratios. LDL from the Republic of Ireland (a region with a high rate of CVD) had greater resistance to $\mathrm{Cu}$-stimulated oxidation than samples obtained from volunteers in other countries. In conclusion, LDL composition did not predict resistance to $\mathrm{Cu}$-stimulated oxidation, nor is there evidence that LDL from volunteers in countries with lower rates of CVD have greater resistance to oxidation.
\end{abstract}

LDL oxidation: Fatty acids: Antioxidants: Tocopherols: Carotenoids

Oxidative modification of LDL has been associated with atherosclerosis and risk of cardiovascular disease (CVD). Oxidised LDL has properties that could explain the development of atherosclerotic plaque via formation and accumulation of 'foam' cells (lipid-laden monocyte-derived macrophage) in the arterial intima (Steinberg \& Witztum, 1990; Witztum \& Steinberg, 1991). Although there is no conclusive evidence suggesting that people with low

\footnotetext{
Abbreviations: CVD, cardiovascular disease; ES, Spain; FR, France; IE, Republic of Ireland; NL, The Netherlands.

* Corresponding author: Dr Mridula Chopra, fax +44 2870 324965, email m.chopra@ulst.ac.uk
} 
resistance to $\mathrm{LDL}$ oxidation have increased risk of CVD, the general consensus is that the two may be related. The oxidation of LDL can be affected by several factors and among these factors, the composition of the LDL particle is believed to have a marked influence on its susceptibility to oxidation (Spranger et al. 1998). LDL particle size (Chait et al. 1992; Tribble et al. 1995), antioxidant content (Jialal, 1993; Abbey et al. 1993; Tertov et al. 1998) and fatty acid composition (Reaven et al. 1993; Louheranta et al. 1996; Aviram \& Eias, 1993), can affect its oxidation. A linoleaterich diet has been reported to increase (Reaven et al. 1993; Louheranta et al. 1996), and an oleate-rich diet to reduce (Aviram \& Eias, 1993), ex vivo oxidizability of LDL particles. Likewise, supplementation with $\alpha$-tocopherol (Dieber-Rothender et al. 1991) and carotenoids (Levy et al. 1995; Agarwal \& Rao, 1998; Hininger et al. 1997) has been reported to protect LDL from oxidation.

Epidemiological studies have indicated a significant inverse correlation between the concentration of vitamin $\mathrm{E}$ and carotenoids in plasma and mortality from CHD (Riemersma et al. 1990; Gey et al. 1991). Recently, plasma $\alpha$-carotene and $\gamma$-tocopherol have been suggested as markers of atherosclerosis and a decrease in their concentration was shown to be associated with the presence of CHD (Kontush et al. 1999). Across Europe, large differences in mortality due to CVD have been reported (Sans et al. 1997). However, the evidence on differences in LDL composition and oxidation of LDL between countries with reported different risk of CVD is lacking.

In the present study, we have compared the concentration of $\alpha$-tocopherol, carotenoid and fatty acid components of LDL isolated from human adult volunteers recruited from five European countries which differ in the rates of CVD; France (FR), Northern Ireland (UK), the Republic of Ireland (IE), The Netherlands (NL) and Spain (ES). We have examined whether there was a relationship between the concentration of variables mentioned earlier and the oxidation resistance of LDL to $\mathrm{Cu}$ determined by measuring the lag phase.

\section{Volunteers and methods}

\section{Volunteers}

Apparently healthy, non-smoking, male and female volunteers, aged 25-45 years, assessed as consuming diets typical of the region, were recruited at five European centres: Grenoble (FR); Coleraine, Nothern Ireland (UK); Cork (IE); Zeist (NL); and Madrid (ES). Volunteers consuming supplements or taking prescribed medication were not included in the study. Those participating in the study were asked to maintain their normal lifestyle during the course of the study. The recruitment objective set by organizing committee was eighty volunteers at each centre (forty male and forty female) and volunteers were checked for normal fasting blood biochemical profiles (haemoglobin concentration, red cell, white cell and platelet count, plasma glucose, cholesterol, triacylglycerol and retinol concentrations). Those included in the study were required to fulfil certain inclusion criteria, which included: plasma cholesterol $<6.8 \mathrm{mmol} / 1$; triacylglycerol $<2.3 \mathrm{mmol} / 1$ and normal blood glucose $<6 \mathrm{mmol} / 1$ (for exclusion of potential diabetics). Results from volunteers with serum retinol $<1.0 \mu \mathrm{mol} / \mathrm{l}$ (three subjects from the UK) were also not included in the study. The reason for choosing a cut-off point for retinol was that low retinol levels indicate an increased susceptibility to infection. The final number of valid volunteers entering the study was $(n)$ : FR 75 (thirtyeight male, thirty-seven female); UK 65 (thirty-two male, thirty-three female); IE 73 (forty male, thirty-three female); NL 72 (thirty-three male, thirty-nine female); ES 64 (thirtytwo male, thirty-two female). However, due to the centralization of analysis and time constraints, not all samples were analysed. The final number of volunteers for whom complete sets of data were obtained are displayed in each of the Tables. Various sex-related as well as plasma characteristics have been published in our previous report (Olmedilla et al. 2001), and are also shown in Table 1. The table also includes the information on CVD death rates published by Sans et al. 1997.

The volunteers signed a written consent form and all relevant ethical committees approved the study.

\section{Blood samples}

Fasting venous blood samples $(5 \mathrm{ml})$ were added to tubes containing lithium heparin as anticoagulant, centrifuged, and plasma transferred to screw-capped Eppendorf tubes, frozen immediately at $-70^{\circ} \mathrm{C}$ and then transported by aircourier over dry ice to F. Hoffmann-La Roche (Basle, Switzerland) for central analysis. The analysis was completed within 1 year of completion of the study.

\section{LDL analysis: fatty acids, tocopherols and carotenoids}

After thawing the plasma, LDL were isolated by density ultracentrifugation on a TL-100 ultracentrifuge (Beckman, Palo Alto, CA, USA) as described previously (Himber et al. 1995). LDL cholesterol concentration was determined using an enzymatic colorimetric test (Roche). LDL lipid, tocopherol and carotenoids were extracted by the method of Folch et al. (1957).

Fatty acid analysis. LDL lipids were extracted with chloroform-methanol, dried under $\mathrm{N}_{2}$ transmethylated with methanolic $\mathrm{HCl}$ and separated by GC (HP 5890A; HewlettPackard, Palo Alto, CA, USA) as detailed previously (Raederstroff et al. 1991). In brief, a fused silica capillary column $(50 \mathrm{~mm}$ length, $0.25 \mathrm{~mm}$ i.d., $0.1 \mathrm{~mm}$ layer thickness) was used with following conditions: injection at $55^{\circ} \mathrm{C}, 10^{\circ} \mathrm{C} / \mathrm{min}$ from $55-177^{\circ} \mathrm{C}, 1^{\circ} \mathrm{C} / \mathrm{min}$ from $177-218^{\circ} \mathrm{C}$, $4^{\circ} \mathrm{C} / \mathrm{min}$ from $218-270^{\circ} \mathrm{C} . \mathrm{C}_{17}$ methyl ester was used as internal standard, and fatty acids were quantified by using commercial methyl ester standards.

Tocopherol and Carotenoid analysis. A sample of $250 \mu \mathrm{l}$ was mixed with $250 \mu \mathrm{l}$ distilled water, deproteinized by addition of $500 \mu \mathrm{l}$ ethanol and mixed on a vortex mixer. To the mixture, $1 \mathrm{ml}$ hexane was added and following mechanical shaking for $10 \mathrm{~min}$ tubes were centrifuged at $2000 \mathrm{~g}$ for $10 \mathrm{~min}$. A sample of the hexane layer $(400 \mu \mathrm{l})$ was evaporated to dryness and samples were re-suspended in mobile phase (acetonitrile-tetrahydrofuran-methanolammonium acetate (10 g/l) (684:220:68:28, by vol.)), and 
separated by $\mathrm{C}_{18}$ reverse-phase HPLC with either fluorimetric (tocopherol) or visible wavelength (carotenoids) spectrophotometric detection (Hess et al. 1991). The stock solutions for calibration were prepared in hexane-butylated hydroxy toluene using pure standards of $\alpha$ - and $\beta$-carotene, lycopene, lutein and $\alpha$ - and $\beta$-tocopherol. The solutions were stable at $-20^{\circ} \mathrm{C}$ for up to 1 month (except lycopene, which was stored up to 1 week only).

\section{LDL oxidation}

$\mathrm{Cu}$-induced LDL oxidation lag-time was measured using the method of Esterbauer et al. (1989) and modified by Himber et al. (1995). Briefly, heparinized plasma was adjusted to a density of $1.21 \mathrm{~g} / \mathrm{ml}$ by addition of solid $\mathrm{KBr}$ and overlaid with $150 \mathrm{mmol} \mathrm{NaCl} / \mathrm{l}$. The samples were centrifuged in a TL-100ultracentrifuge (Beckman) for $25 \mathrm{~min}$ at $10^{\circ} \mathrm{C}$ and $440000 \mathrm{~g}$. The LDL layer was removed by slicing the polycarbonate tube and used directly for the LDL oxidation. Cu-initiated oxidation of LDL was followed up to $5 \mathrm{~h}$ by measuring diene conjugate formation at $234 \mathrm{~nm}$. The lag phase was determined as the intercept of the tangents drawn to the segments of the absorbance curve corresponding to propagation phase, as described by Frei \& Gaziano (1993).

\section{Statistical analysis}

All data was $\log _{10}$-transformed to normalize distributions and/or to produce homogeneous variances. A comparison within sex, at baseline, between centres (FR, UK, IE, NL and ES), of plasma LDL tocopherols, carotenoids, fatty acids, and $\mathrm{Cu}$-induced LDL-oxidation lag-times, was undertaken by one-way ANOVA. Where the variance ratio ( $F$ test) was significant $(P<0 \cdot 05)$, comparison between the means for all centres was undertaken by using the Scheffé post-hoc test. Within each centre, the mean for females for each variable was compared with the male counterpart, using Student's unpaired $t$ test. Associations between $\mathrm{Cu}$-induced LDL-oxidation lag-times and facets of LDL composition (i.e. tocopherol, carotenoid and fatty acid components) were assessed by regression analysis.

\section{Results}

Blood sample collection was done between the months of January and March. During this period minimum fluctuations are known to occur in plasma concentration of antioxidant micronutrients (Van de Vijver et al. 1997). In addition, seasonal and day-to-day variations in the LDL lagphase, micronutrients and the fatty acid composition of LDL are reported to be low in unsupplemented subjects (Van de Vijver et al. 1997; Cantilena et al. 1992; Chopra et al. 2000). The subjects were advised to maintain their normal dietary habits. The results of the present study are therefore unlikely to be influenced by the seasonal and day-to-day variations in variables.

\section{LDL concentration of tocopherols and carotenoids}

Within centres (except for ES), there were generally no 
A. J. A. Wright et al.

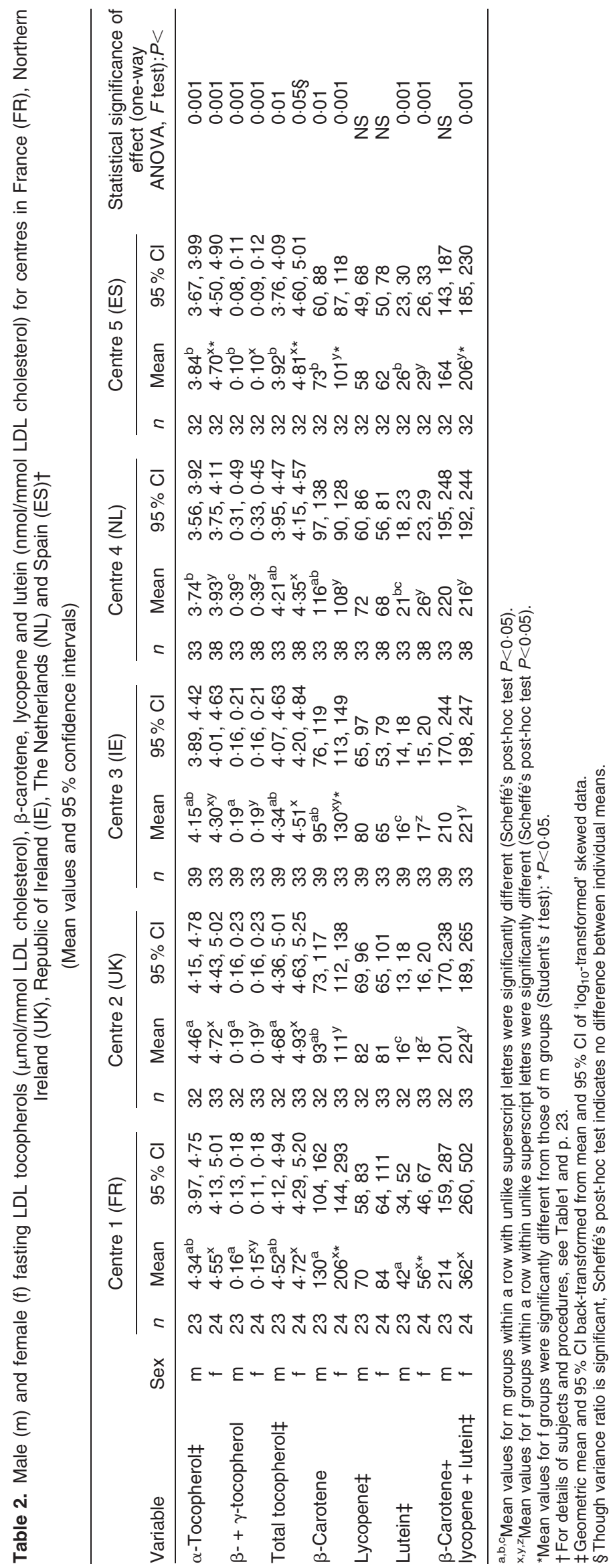




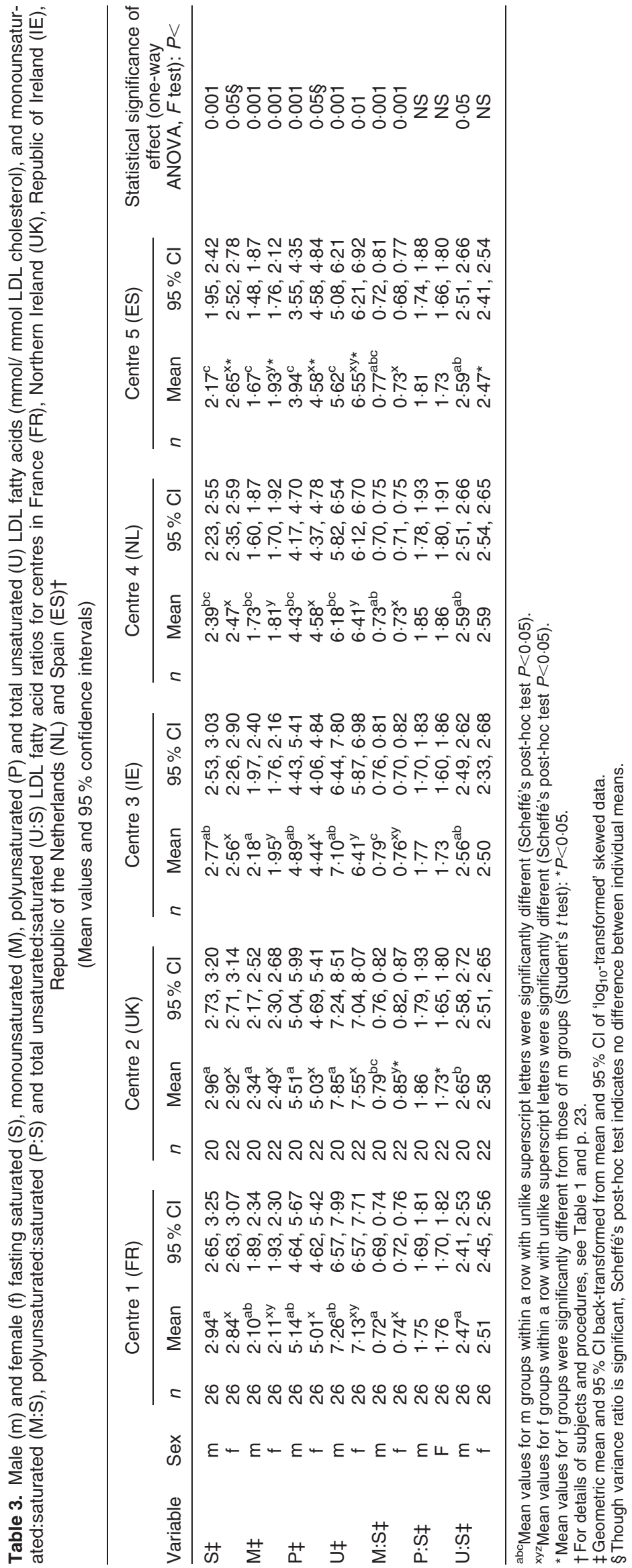


differences between sexes for most of the variables (Table 2). Between centres, $\alpha$-tocopherol concentrations of LDL were low in Dutch volunteers. In males, the results reached significance compared with UK only, and in females they were significantly lower compared with all centres except IE. $\beta$-+ $\gamma$-tocopherol were significantly higher in Dutch compared with all other participating centres both for males and females $(P<0 \cdot 001)$. In females, total tocopherol concentration was not significantly different between centres, but for male volunteers, total tocopherol was significantly different between ES and UK.

LDL $\beta$-carotene concentrations were significantly different between ES and FR with ES showing the lowest $\beta$ carotene and FR the highest (Table 2). The values for the other three centres (IE, NL, UK) were not significantly different from each other. LDL lycopene was not significantly different between any centres. LDL lutein was significantly higher for FR (almost twofold compared with NL and threefold compared with UK and IE) compared with all centres (Table 2, $P<0 \cdot 001$ ) in the order FR $>\mathrm{ES}>$ $\mathrm{NL}>\mathrm{IE}$ and UK. When the total LDL carotenoid concentrations (sum of $\beta$-carotene, lutein and lycopene) were compared, no differences emerged for males. In the case of females, FR showed significantly higher total carotenoid concentration compared with all other centres (Table 2, $P<0 \cdot 001$ ). The remaining four centres were not significantly different.

\section{LDL concentration of fatty acids}

Some differences between regions in LDL concentrations of absolute saturated, monounsaturated, polyunsaturated and total unsaturated fatty acids were observed. In male volunteers, LDL saturated fatty acid content was not significantly different among the volunteers from FR, UK and IE, but only subjects from FR and UK showed a significantly higher concentration than those from NL and ES (Table 3, $P<0 \cdot 001$, one way ANOVA). In females, differences were not significant. There were minor differences in the mono and polyunsaturated FA content of LDL and in general LDL from UK volunteers showed highest unsaturated FA concentrations, though not significantly different from other centres (except for ES males). The unsaturated:saturated fatty acid ratio was significantly different only between male volunteers from UK and FR.

\section{LDL lag-phase comparisons}

Ex vivo resistance of $\mathrm{LDL}$ to $\mathrm{Cu}$-initiated oxidation was highest in UK (both male and female) compared with the other four centres (Table 4). The order of LDL's resistance to oxidation was $\mathrm{UK}>\mathrm{IE}>\mathrm{ES}>\mathrm{FR}>\mathrm{NL}$. Lag phases were not significantly different between the two Irish populations (UK and IE). No significant correlation was observed between the LDL lag-phase and other variables, i.e. fatty acid, carotenoid and tocopherol content of LDL for either the combined or separate data for countries. There were no correlations between lag phase with lipid-standardized LDL tocopherol and carotenoid levels. LDL composition did not correlate with the CVD mortality rates reported by Sans et al. (1997). However, when the LDL lag-phase from 
five centres was compared with incidence rates of CVD reported by Sans et al. (1997) a significant positive correlation was observed both for males and females ( $r 0.905$ and 0.915 respectively, $P<0.05$ ).

\section{Discussion}

The five European regions studied (Grenoble, FR; Coleraine, Northern Ireland, UK; Cork, IE; Zeist, NL, and Madrid, ES) lie on a north-south axis and the population in southern Europe has a lower mortality from cardiovascular disease than those from the northern and eastern parts (World Health Organization, 1993). In the present study, a similar age group (25-45 years) was compared between the countries and the homogeneity of inclusion criteria and centralization of the analysis would have minimized the analytical CV.

Minor differences were observed between regions for LDL $\alpha$-tocopherol concentration. It is however, interesting to note that Dutch volunteers had significantly lower $\alpha$ tocopherol and higher $\beta-+\gamma$-tocopherol concentration than other participating centres. Both $\alpha$-and $\gamma$-tocopherol have been reported to compete for their incorporation in lipoprotein particles in the liver (Traber et al. 1989), and supplementation with $\gamma$-tocopherol-rich corn oil has been reported to decrease the plasma $\alpha$-tocopherol (Elmadfa \& Park, 1999). It is therefore not surprising that the population with high LDL content of $\alpha$-tocopherol shows low $\beta-+\gamma$ tocopherol in the LDL and vice versa. However, in the present study, in Dutch subjects, we did not find any significant correlation between $\alpha$ - and $\beta$ - $+\gamma$-tocopherol.

Previously, it has been shown that in supplemented subjects, changes in dietary intake of carotenoids leads to a change in their concentrations in plasma and LDL (Chopra et al. 2000). Therefore, plasma and LDL carotenoids may be considered as biomarkers of fruit and vegetable intake (Scott et al. 1994; Parker, 1997). In the present study, ES, the southernmost country (a 'Mediterranean' region perceived to have a fruit and vegetable consumption relatively greater than the northernmost regions) had the lowest LDL concentrations of $\beta$-carotene and lycopene. On comparison of the dietary intake and plasma carotenoid concentrations, Spanish volunteers were found to have a lowest carotenoid intake, $9.5 \mathrm{mg} / \mathrm{d}$ compared with $16.1 \mathrm{mg} / \mathrm{d}$ in the French and approximately $14 \mathrm{mg} / \mathrm{d}$ in subjects from the other three centres (UK, IE, NL; O'Neill et al. 2001). The plasma concentration of carotenoids in the Spanish subjects were also found to be low (Olmedilla et al. 2001). It is therefore not surprising that LDL concentration of carotenoids was low in the Spanish. Previously, it was reported that there are regional differences in the fruit and vegetable intakes within ES, however, the fruit and vegetable consumption in Madrid is reported to be similar to that consumed on average in ES (Instituto Nacional de Estadistica, 1994). Although the Spanish are perceived to be high consumers of fruits and vegetables, the results of the present study and our previous reports (O'Neill et al. 2001; Olmedilla et al. 2001) show that the volunteers from Madrid consumed less vegetables, and had lower plasma carotenoids and LDL than the subjects from other participating centres. It can be argued that the participants were not necessarily representatives of the overall population of their respective countries. However, since CI indicate a high precision in the estimation of means, one can extrapolate the results of the present study to populations with similar characteristics. It is interesting to note that a previous comparative study (Howard et al. 1996) between southern FR and Northern Ireland reported very similar results to those obtained in the present European Union study. The mean plasma lutein concentrations of adult French men and women reported by Howard et al. (1996) were double in subjects from Toulouse, FR, than matched group of Irish subjects from Belfast Northern Ireland, UK $(P<0.001)$. In the present study, LDL lutein was also two to threefold higher in the subjects from Grenoble, FR, than those in Coleraine, UK. It is also interesting to note that the LDL carotenoid and tocopherol concentrations in both Irish populations (Coleraine (UK) and Cork (IE)) were not significantly different. Toulouse and Grenoble are on opposite sides of FR, and Cork and Coleraine lie at the opposite ends of IE. Therefore, at least for France and Ireland the results of the present study can be extrapolated to the respective population of those countries.

Saturated fat is believed to increase the risk of CVD through its hypercholesterolaemic effect (Mazier \& Jones, 1997; Salter et al. 1998) and previously (Sans et al. 1997) in men, a twofold difference in the risk of CVD was reported for the participating countries of the present study. Nevertheless, in the present study, in male volunteers, only small differences were observed in LDL saturated fatty acid content with concentrations in ES being lower than those in FR, UK and IE but not significantly different from those in the NL. ES is a country with a low risk of CVD, but in addition to the low concentrations of saturated fat, the male volunteers in ES also had the lowest concentrations of polyunsaturated fatty acids. Polyunsaturated fatty acids are considered beneficial due to their lipid-lowering effects, especially on LDL cholesterol (Howard et al. 1995; Carmena et al. 1996; Mazier \& Jones, 1997). However, polyunsaturated fats are more prone to oxidation than saturated fats and increased dietary intake of polyunsaturated fatty acids may increase the susceptibility to ex vivo LDL oxidation (Reaven et al. 1993, Louheranta et al. 1996) and hence the atherogenic properties of the LDL particle. In the present study, LDL fatty acids (both saturated and unsaturated) were highest in volunteers from the UK, and surprisingly the LDL from the UK were more resistant to oxidation than other participating centres and showed the highest lag phase. This suggests that LDL content of tocopherols, carotenoids, and fatty acids alone cannot predict susceptibility of LDL to oxidation. This is supported by the observations of Dieber-Rothender et al. (1991) who reported that in unsupplemented subjects there are no correlations between the LDL content of tocopherols and the resistance of LDL to oxidation. There were no significant relationships between the lipid-soluble antioxidant content or fatty acid composition, and ex vivo LDL resistance to $\mathrm{Cu}$-induced oxidation. Neither the LDL polyunsaturated fatty acid nor the lipid-soluble antioxidant composition predicted the resistance of LDL to oxidation. Surprisingly, a significant positive correlation was observed between the LDL lag-times and incidence of CVD reported 
by Sans et al. (1997). At present, we have no obvious explanation for the observed correlations.

Results of the present study show no evidence that LDL from volunteers in regions with the lower rates of CVD have greater ex vivo resistance to $\mathrm{Cu}$-induced $\mathrm{LDL}$ oxidation. French subjects are reported to be at a low risk of CVD compared with the Irish, yet, the UK and IE samples were more resistant to oxidation than those of French. The higher resistance of $\mathrm{LDL}$ from the Irish volunteers to $\mathrm{Cu}$-induced oxidation appears to be at odds with their generally higher rates of early deaths from CVD (Sans et al. 1997) compared with French or Spanish subjects. The current study also indicates that a region perceived to have a high fruit and vegetable consumption i.e. $\mathrm{ES}$, does not equate with having high LDL concentrations of lipid-soluble antioxidants. Only LDL lutein concentration showed a clear inverse relationship with the risk of CVD in the five European countries (Sans et al. 1997). Green vegetables are a rich source of lutein (International Agency for Research on Cancer, 1998) and high plasma LDL lutein concentration indicates high consumption of green vegetables in volunteers (Thurnham et al. 1998; Chopra et al. 2000). These observations further support the previous suggestions by Howard et al. (1996) that low blood hydroxy-carotenoids may be a good indicator of increased CVD risk. Concentrations of other carotenoids, tocopherols, fatty acids and LDL oxidizability did not follow the same pattern as described for the CVD risk between countries, as well as lutein. Due to the restrictions of the 'inclusion criteria' in the present study, it could be argued that volunteers were not representatives of the populations of their respective countries. However, as explained earlier, since the information obtained in this study for IE and FR agrees with previous studies undertaken in different regions of respective countries, we believe that at least for these two countries, volunteers can be considered representative of the rest of the population.

The results of the present study did not show any relationship between the fatty acid profile or the antioxidant content of LDL and ex vivo resistance of $\mathrm{LDL}$ to $\mathrm{Cu}-$ induced oxidation in healthy subjects from five areas in Europe with different CVD mortality rates. Furthermore, there were no clear inter-relationships between populationbased CVD mortality data and the composition of LDL in the healthy subjects included in the present study. In conclusion, we believe that the fatty acid and antioxidant (tocopherols and carotenoids) composition of LDL alone and its resistance to ex vivo oxidation may not necessarily provide clues to the risk of CVD incidence.

\section{Acknowledgements}

The authors are grateful to Gary Wortley (Institute of Food Research, Norwich, Norfolk, UK), for his contribution to the analyses. They also acknowledge the contribution made by researchers at each study centre in the recruitment and supplementation of volunteers, and the collection and processing of blood samples; in particular Maura O'Neill and Una McLoone (UK), Yvonne Carroll (IE) and Immaculada Blanco and Enrique Gil-Martinez (ES). Financial support was provided by the European Union
(AIR 2-CT93-0888) and the Swiss Federal Office for Education and Science (Nr. 93.0391).

\section{References}

Abbey M, Nestel PJ \& Baghurst PA (1993) Antioxidant vitamins and low-density-lipoprotein oxidation. American Journal of Clinical Nutrition 58, 525-532.

Agarwal S \& Rao AV (1998) Tomato lycopene and low-density lipoprotein oxidation: A human dietary intervention study. Lipids 33, 981-984.

Aviram M \& Eias JK (1993) Dietary olive oil reduces low-density lipoprotein uptake by macrophages and decreases the susceptibility of the lipoprotein to undergo lipid peroxidation. Annals of Nutrition and Metabolism 37, 75-84.

Cantilena LR, Stukel TA, Greenberg ER, Nann S \& Nierenberg DW (1992) Diurnal and seasonal variation of five carotenoids measured in human serum. American Journal of Clinical Nutrition 55, 659-663.

Carmena R, Ascaso JF, Camejo G, Varela G, Hurt-Camejo E, Ordovas JM, Martinez-Valls J, Bergstom M \& Wallin B (1996) Effect of olive and sunflower oils on low density lipoprotein level, composition, size, oxidation and interaction with arterial proteoglycans. Atherosclerosis 125, 243-255.

Chait A, Ronald MD \& Tribble DL (1992) Susceptibility of small, dense low-density lipoproteins to oxidative modification in volunteers with the atherogenic lipoprotein phenotype, Pattern B. American Journal of Clinical Medicine 94, 350-356.

Chopra M, Kavanagh S, Fitzsimons P \& Thurnham DI (2000) Variations in the serum cholesterol, ferric reducing ability of plasma and LDL lag phase in unsupplemented human subjects. Proceedings of the Nutrition Society 59, 21A.

Chopra M, O'Neill ME, Keogh N, Wortley G, Southon S \& Thurnham DI (2000) Influence of increased fruit and vegetable intake on plasma and lipoprotein carotenoids and LDL oxidation in smokers and non-smokers. Clinical Chemistry 46, $1818-1829$.

Dieber-Rothender M, Puhl H, Waeg G, Streigl G \& Esterbauer H (1991) Effect of oral supplementation with D- $\alpha$-tocopherol on the vitamin E content of human low density lipoproteins and resistance to oxidation. Journal of Lipid Research 32, $1325-1332$.

Elmadfa I \& Park E (1999) Impact of diets with corn oil or olive/sunflower oils on DNA damage in healthy young men. European Journal of Nutrition 38, 286-292.

Esterbauer H, Striegl G, Puhl H \& Rotheneder M (1989) Continuous monitoring of in vitro oxidation of human low density lipoprotein. Free Radical Research Communications 6, $67-75$.

Folch J, Lees M \& Stanley GHS (1957) A simple method for the isolation and purification of total lipides from animal tissues. Journal of Biological Chemistry 226, 497-509.

Frei B \& Gaziano JM (1993) Content of antioxidants, preformed lipid hydroperoxides, and cholesterol as predictors of the susceptibility of human LDL to metal ion-dependent and independent oxidation. Journal of Lipid Research 34, 2135-2145.

Gey KF, Puska P, Jordan P \& Moser UK (1991) Inverse correlation between vitamin $\mathrm{E}$ and mortality from ischaemic heart disease in cross-cultural epidemiology. American Journal of Clinical Nutrition 53, 326S-334S.

Hess D, Keller HE, Oberlin B, Bonfanti R \& Schüep W (1991) Simultaneous determination of retinol, tocopherols, carotenes and lycopene in plasma by means of high-performance liquid chromatography on reversed phase. International Journal for Vitamin and Nutrition Research 61, 232-238. 
Himber J, Buhler E, Moll D \& Moser UK (1995) Low density lipoprotein for oxidation and metabolic studies. Isolation from small volumes of plasma using a tabletop ultracentrifuge. International Journal for Vitamin and Nutrition Research $\mathbf{6 5}$, $137-142$.

Hininger I, Chopra M, Thurnham DI, Laporte F, Richard MJ, Favier A \& Roussell AM (1997) Effect of increased fruit and vegetable intake on the susceptibility of lipoprotein to oxidation in smokers. European Journal of Clinical Nutrition 51, 601-606.

Howard AN, Williams NR, Palmer CR, Cambou JP, Evans AE, Foote JW, Marques-Vidal P, McCrum EE, Ruidavets JB, Nigdikar SV, Rajput-Williams J \& Thurnham DI (1996) Do hydroxy-carotenoids prevent coronary heart disease? A comparison between Belfast and Toulouse. International Journal for Vitamin and Nutrition Research 66, 113-118.

Howard BV, Hannah JS, Heiser CC, Jablonski KA, Paidi MC, Alarif L, Robbins DC \& Howard WJ (1995) Poly-unsaturated fatty acid result in greater cholesterol lowering and less triacylglycerol elevation than do mono-unsaturated fatty acids. American Journal of Clinical Nutrition 62, 392-402.

Instituto Nacional de Estadistica (National Institute of Statistics (1994) Encuesta de prespuestos familiaries 1990-1991 (Survey of family budgets 1990-1991). Madrid: Instituto Nacional de Estadistica, Vol. 2.

International Agency for Research on Cancer (1998) IARC Handbooks of Cancer Prevention, Lyon: IARC Press.

Jialal I (1993) The effect of antioxidant dietary micronutrients on LDL oxidation. Implications for atherosclerotic prevention. Canadian Journal of Cardiology 9, B11-B13.

Kontush A, Spranger T, Reich A, Baum K \& Beisiegel U (1999) Lipophilic antioxidants in blood plasma as markers of atherosclerosis: the role of alpha-carotene and gammatocopherol. Atherosclerosis 144, 117-122.

Levy Y, Ben-Amotz A \& Aviram M (1995) Effect of different $\beta$ carotene isomers on lipoprotein oxidative modification. Journal of Nutrition Environmental Medicine 5, 13-22.

Louheranta Am, Porkkala-Sarataho EK, Nyyssonen MK, Salonen RM \& Salonen JT (1996) Linoleic acid intake and susceptibility of very low-density and low-density lipoproteins to oxidation in men. American Journal of Clinical Nutrition 63, 698-703.

Mazier MJ \& Jones PJ (1997) Diet fat saturation and feeding state modulate rates of cholesterol synthesis in normolipidaemic men. Journal of Nutrition 127, 332-340.

Olmedilla B, Granado F, Southon S, Wright AJA, Blanco I, GilMartinez E, van den Berg H, Corridan B, Roussel AM, Chopra M \& Thurnham DI (2001) Serum concentrations of carotenoids, vitamins $\mathrm{A}, \mathrm{E}$ and $\mathrm{C}$, in control volunteers from five European countries. British Journal of Nutrition 85, 227-238.

O'Neill M, Carroll Y, Corridan B, Olmedilla B, Granado F, Blanco L, van den Berg H, Hininger I, Rousell A-M, Chopra M, Southon S \& Thurnham DI (2001) A European carotenoid database to assess carotenoid intakes and its use in a five-country comparative study. British Journal of Nutrition 85, 499-507.

Parker R (1997) Bioavailability of carotenoids. European Journal of Clinical Nutrition 51, S86-S90.

Raederstorff D, Meier CA, Moser U \& Walter P (1991) Hypothyroidism and thyroxine susbstitution affect the $n-3$ fatty acid composition of rat liver mitochondria. Lipids 26, $781-787$.

Reaven PD, Parthasarthy S, Grasse BJ, Miller E, Steinberg D \& Witztum JL (1993) Effects of oleate-rich and linoleate-rich diets on the susceptibility of low-density lipoproteins to modification in mildly hypercholesterolemic volunteers. Journal of Clinical Investigation 91, 668-676.

Riemersma RA, Oliver M, Elton RA, Alfthan G, Vartiainen E, Salo M, Rubba P, Mancini M, Georgi H, Vuilleumier J-P \& Gey KF (1990) Plasma antioxidants and coronary heart disease: vitamins $\mathrm{C}$ and E, and selenium. European Journal of Clinical Nutrition 44, 143-150.

Salter AM, Mangiapane EH, Bennett AJ, Bruce JS, Billett MA, Anderton KL, Marenah CB, Lawson N \& White DA (1998) The effect of different dietary fatty acids on lipoprotein metabolism: concentration-dependent effects of diets enriched in oleic, myristic, palmitic and stearic acids. British Journal of Nutrition 79, 195-202.

Sans S, Kesteloot H, Kromhout D on behalf of the Task Force (1997) The burden of cardiovascular disease mortality in Europe. Task Force of the European Society of Cardiology on cardiovascular mortality and morbity statistics in Europe (corrected and republished with original paging, article originally printed in European Heart Journal 18, 1231-1248.

Scott KJ, Thurnham DI, Hart DJ \& Bingham SA (1994) The correlation between intake of lutein, lycopene and $\beta$-carotene from vegetables and fruits and concentrations in blood plasma. Proceedings of the Nutrition Society 53, 138A.

Spranger T, Finch B, Fingerhut R, Kohlschutter A, Beisiegel U \& Kontush A (1998) How different constituents of human plasma and low density lipoprotein determine plasma oxidizability by copper. Chemistry and Physics of Lipids 91, 39-52.

Steinberg D \& Witztum JL (1990) Lipoproteins and atherogenesis. Journal of the American Medical Association 264, 3047-3052.

Tertov VV, Sobenin IA, Kaplun VV \& Orekhov AN (1998) Antioxidant content in low-density lipoprotein and lipoprotein oxidation in vivo and in vitro. Free Radical Research 29, $165-173$.

Thurnham DI, Northrop-Clewes CA \& Chopra M (1998) Biomarkers of vegetable and fruit intakes. American Journal of Clinical Nutrition 68, 756-757.

Traber MG \& Kayden HJ (1989) $\alpha$-Tocopherol as compared with $\gamma$-tocopherol is preferentially secreted in human lipoproteins. Annals of the New York Academy of Sciences 570, 95-108.

Tribble DL, Krauss RM, Lansberg MG, Thiel PM \& Vandenberg JJM (1995) Greater oxidative susceptibility of the surface monolayer in small dense LDL may contribute to differences in copper induced oxidation among LDL density subfractions. Journal of Lipid Research 36, 662-671.

Van de Vijver LPL, van Duyvenvoorde W, Buytenhek R, van der Laarse A, Kardinaal AFM, van den Berg H \& Princen HMG (1997) Seasonal variation in low density lipoprotein oxidation and antioxidant status. Free Radical Research 27, 89-96.

Witztum JL \& Steinberg D (1991) Role of oxidized low density lipoprotein in atherogenesis. Journal of Clinical Investigation 88, $1785-1792$.

World Health Organization/Food and Agriculture Organization (1993) Food and Health Indicators in Europe: Nutrition and Health 1961-1990, Copenhagen: WHO. 